\title{
Numerical Simulation of Flow Field Characteristics of The Cooling Water Jacket of A Marine Diesel Engine
}

\author{
Bo Zhang ${ }^{1}$, Ping Zhang ${ }^{1, *}$, Zhao Zhang ${ }^{2}$, Shaobo Yang ${ }^{3}$, Chengli Wang ${ }^{4}$, Fanming Zeng ${ }^{1}$ \\ ${ }^{1}$ College of Power Engineering, Naval Univ. of Engineering, Wuhan, P. R. China, 430000 \\ ${ }^{2}$ The First Military Representative Office of Naval Equipment Department of PLA in Wuhan, Wuhan, P. R. China, 430000 \\ ${ }^{3}$ Unit 92730 of the Chinese People's Liberation Army, Sanya, P. R. China, 572000 \\ ${ }^{4}$ Unit 92020 of the Chinese People's Liberation Army, Qingdao, P. R. China, 266000
}

\begin{abstract}
In order to evaluate the flow field characteristics of a marine diesel engine cooling water jacket, and provide a theoretical basis for further optimizing the water jacket structure. A computational fluid dynamics (CFD) method was used to calculate the three-dimensional flow field of the water jacket. Based on the CFD simulation model of the engine water jacket, the analysis of pressure field, velocity field, streamline distribution and flow uniformity of water jacket of diesel engine under rated condition were carried out. The results show that: the total pressure loss of water jacket is $30.3 \mathrm{kPa}$, in which the pressure loss of cylinder block is $8.4 \mathrm{kPa}$, and the one of cylinder head and outlet manifold is $21.9 \mathrm{kPa}$, which indicates that the flow resistance design of the cylinder block and head is reasonable; the flow rate of coolant in the nose zone of cylinder head is above $1.5 \mathrm{~m} / \mathrm{s}$, which meets the cooling demand of cylinder head; the cooling water flows circumferentially in the engine block water jacket, and the flow dead zones are easily formed by the mutual extrusion and collision of the water flows; the outlet of the cylinder head water jacket is connected with the outlet manifold at right angle, which leads to large energy loss of the flow field; the maximum non-uniformity of flow rate of water jacket of each cylinder is $5.85 \%$, which can be further optimized by adjusting the position of water jacket inlet.
\end{abstract}

\section{Introduction}

With the rapid increase of the power per unit volume and the power per liter of modern marine diesel engine, the heat load is obviously increased, and the cooling problem is becoming more and more prominent. The risk of thermal failure of the cylinder head and the engine block is increasing due to the high heat load. Therefore, it is of great significance to analyze the flow field characteristics of the cooling water jacket for optimizing the structure of the cooling system, improving the cooling efficiency and reducing the heat load of the cylinder head and block. [14]. Computational fluid dynamics (CFD) method is used to simulate the cooling water jacket of internal combustion engine, which can obtain a lot of detailed flow information of cooling water jacket, including velocity distribution, pressure distribution and streamline distribution. The calculation results can evaluate the flow field characteristics of cooling water jacket and point out the direction for further improving the cooling system structure [5-8].

In 2003, Chen of Jilin University used FLUENT software to simulate the cooling water jacket of CA498 diesel engine, and selected the optimized short water jacket scheme. In 2012, Lei and Shen carried out threedimensional CFD analysis on the cooling water jacket of cylinder block and head of an internal combustion engine.
The influence of back pressure at the outlet of cylinder head water jacket on the flow characteristics of coolant in the water jacket was analyzed, and the overall cooling system was optimized and improved [9]. In 2013, Stefano and Matteo carried out CFD analysis and optimization on the water jacket of engine cylinder block and cylinder head. The influence of the position and diameter of the water jacket inlet and the position and diameter of the upper water hole on the flow field characteristics of the cooling water jacket is analyzed [10]. In 2018, W. Junjie of Zhejiang University used computational fluid dynamics (CFD) to calculate the flow field of water jacket in cylinder head of diesel engine, and compared and analyzed the streamline diagram and velocity vector diagram measured by CFD simulation and PIV test. The results show that the flow field distribution obtained by the two methods is roughly the same [11].

In order to evaluate the flow field characteristics of the cooling water jacket of a marine diesel engine and provide the basis for further improving the structure of the cooling water jacket, the 3D CFD simulation of the cooling water jacket of the engine block and cylinder head was carried out by using FLUENT software, and the accuracy of the simulation results was verified by experiments. Based on the CFD simulation model, the pressure field analysis, velocity field analysis and flow uniformity analysis of each cylinder are carried out under the rated condition of

* Corresponding author: 821021174@qq.com 
diesel engine. It points out the direction for further improving the structure of cooling water jacket.

\section{CFD calculation theory}

Computational fluid dynamics (CFD) is a combination of numerical calculation, modern fluid mechanics and computer science, which has the advantages of economy, high efficiency, powerful function and comprehensive calculation results [12-13].

\subsection{Controling equations}

It is assumed that the flow field is three-dimensional viscous incompressible turbulent flow. This paper only studies the flow field characteristics of cooling water jacket without considering the heat transfer problem, so the energy equation is not considered.

(1) Mass Conservation Equation

$$
\frac{\partial \rho}{\partial t}+\frac{\partial(\rho u)}{\partial x}+\frac{\partial(\rho v)}{\partial y}+\frac{\partial(\rho w)}{\partial z}=0
$$

where $\rho$ is the density, $t$ is the time, and $u, v$ and $w$ are the components of the velocity vector in the $\mathrm{x}, \mathrm{y}$ and $\mathrm{z}$ directions. If the fluid is incompressible and the density is constant, Eq. (1) can be written as follows:

$$
\frac{\partial u}{\partial x}+\frac{\partial v}{\partial y}+\frac{\partial w}{\partial z}=0
$$

(2) Momentum Conservation Equation

$$
\begin{gathered}
\frac{\partial(\rho u)}{\partial t}+\operatorname{div}(\rho u U)=\operatorname{div}(\mu \operatorname{grad} u)-\frac{\partial p}{\partial x}+S_{u} \\
\frac{\partial(\rho v)}{\partial t}+\operatorname{div}(\rho v U)=\operatorname{div}(\mu \operatorname{grad} v)-\frac{\partial p}{\partial y}+S_{v} \\
\frac{\partial(\rho w)}{\partial t}+\operatorname{div}(\rho w U)=\operatorname{div}(\mu \operatorname{grad} w)-\frac{\partial p}{\partial z}+S_{w}
\end{gathered}
$$

where $\mu$ is the dynamic viscosity, $\operatorname{div}(U)=\frac{\partial U_{x}}{\partial x}+\frac{\partial U_{y}}{\partial y}+$ $\frac{\partial U_{z}}{\partial z}, \mathrm{U}$ is the velocity vector; $\operatorname{grad} u=\frac{\partial u}{\partial x}+\frac{\partial u}{\partial y}+\frac{\partial u}{\partial z}, \mathrm{p}$ is the pressure on the fluid micro element; $S_{u}, S_{v}, S_{w}$ is the generalized source term of momentum conservation equation.

For incompressible fluid with constant viscosity, the momentum conservation equation can be expressed as follows:

$$
\begin{array}{r}
\frac{\partial(\rho u)}{\partial t}+\frac{\partial(\rho u u)}{\partial x}+\frac{\partial(\rho u v)}{\partial y}+\frac{\partial(\rho u w)}{\partial z}=\frac{\partial}{\partial x}\left(\mu \frac{\partial u}{\partial x}\right)+ \\
\frac{\partial}{\partial y}\left(\mu \frac{\partial u}{\partial y}\right)+\frac{\partial}{\partial z}\left(\mu \frac{\partial u}{\partial z}\right)-\frac{\partial p}{\partial x}+S_{u} \\
\frac{\partial(\rho v)}{\partial t}+\frac{\partial(\rho v u)}{\partial x}+\frac{\partial(\rho v v)}{\partial y}+\frac{\partial(\rho v w)}{\partial z}=\frac{\partial}{\partial x}\left(\mu \frac{\partial v}{\partial x}\right)+ \\
\frac{\partial}{\partial y}\left(\mu \frac{\partial v}{\partial y}\right)+\frac{\partial}{\partial z}\left(\mu \frac{\partial v}{\partial z}\right)-\frac{\partial p}{\partial y}+S_{v} \\
\frac{\partial(\rho w)}{\partial t}+\frac{\partial(\rho w u)}{\partial x}+\frac{\partial(\rho w v)}{\partial y}+\frac{\partial(\rho w w)}{\partial z}=\frac{\partial}{\partial x}\left(\mu \frac{\partial w}{\partial x}\right)+ \\
\frac{\partial}{\partial y}\left(\mu \frac{\partial w}{\partial y}\right)+\frac{\partial}{\partial z}\left(\mu \frac{\partial w}{\partial z}\right)-\frac{\partial p}{\partial z}+S_{w}(8)
\end{array}
$$

\subsection{Turbulence model}

In the turbulence description of internal combustion engine flow field, The most widely used model is the $\mathrm{k}-\varepsilon$ two equations model:

$$
\mu_{\tau}=C_{\mu} \rho \frac{k^{2}}{\varepsilon}
$$

where $k=\frac{1}{2}\left\langle u_{i}^{\prime} u_{i}^{\prime}\right\rangle$ is the turbulent kinetic energy, reflecting the characteristic velocity, $\varepsilon=\frac{\mu}{\rho}\left\langle\frac{\partial u_{i}^{\prime}}{\partial x_{i}} \frac{\partial u_{i}^{\prime}}{\partial x_{i}}\right\rangle$ is the viscous dissipation rate of turbulence, reflecting the characteristic length scale.

$\mathrm{k}$ and $\varepsilon$ are regarded as dependent variables and determined by their respective differential equations. The equations of $\mathrm{k}$ and $\varepsilon$ are as follows:

$$
\begin{gathered}
\frac{\partial(\rho k)}{\partial t}+\frac{\partial\left(\rho k u_{i}\right)}{\partial x_{i}}=\frac{\partial}{\partial x_{j}}\left[\left(\mu+\frac{\mu_{\tau}}{\sigma_{k}}\right) \frac{\partial k}{\partial x_{j}}\right]+G_{k}+G_{b}-\rho \varepsilon-Y_{M} \\
\frac{\partial(\rho \varepsilon)}{\partial t}+\frac{\partial\left(\rho \varepsilon u_{i}\right)}{\partial x_{i}}=\frac{\partial}{\partial x_{j}}\left[\left(\mu+\frac{\mu_{\tau}}{\sigma_{\varepsilon}}\right) \frac{\partial \varepsilon}{\partial x_{j}}\right]+C_{1 \varepsilon} \frac{\varepsilon}{k}\left(G_{k}+\right. \\
\left.C_{3 \varepsilon} G_{b}\right)-C_{2 \varepsilon} \rho \frac{\varepsilon^{2}}{k}
\end{gathered}
$$

where $G_{b}$ represents the turbulent kinetic energy generation term caused by buoyancy. For incompressible flow, $G_{b}=0 . Y_{M}=0, Y_{M}$ is the expansion of pulsation in compressible turbulence, For incompressible flow, $Y_{M}=0 . G_{k}$ represents the generation term of turbulent kinetic energy k caused by the average velocity gradient, which is calculated by the following formula:

$$
G_{k}=\mu_{\tau}\left(\frac{\partial u_{i}}{\partial x_{j}}+\frac{\partial u_{j}}{\partial x_{i}}\right) \frac{\partial u_{i}}{\partial x_{j}}
$$

Therefore, when the flow is incompressible, the standard $\mathrm{k}-\varepsilon$ model becomes:

$$
\begin{gathered}
\frac{\partial(\rho k)}{\partial t}+\frac{\partial\left(\rho k u_{i}\right)}{\partial x_{i}}=\frac{\partial}{\partial x_{j}}\left[\left(\mu+\frac{\mu_{\tau}}{\sigma_{k}}\right) \frac{\partial k}{\partial x_{j}}\right]+G_{k}-\rho \varepsilon \\
\frac{\partial(\rho \varepsilon)}{\partial t}+\frac{\partial\left(\rho \varepsilon u_{i}\right)}{\partial x_{i}}=\frac{\partial}{\partial x_{j}}\left[\left(\mu+\frac{\mu_{\tau}}{\sigma_{\varepsilon}}\right) \frac{\partial \varepsilon}{\partial x_{j}}\right]+C_{1 \varepsilon} \frac{\varepsilon}{k} G_{k}-C_{2 \varepsilon} \rho \frac{\varepsilon^{2}}{k}
\end{gathered}
$$

According to the value recommended by Lauder et al and the later experimental verification, The value of the constant $C_{1 \varepsilon}, C_{2 \varepsilon}, C_{\mu}, \sigma_{k}, \sigma_{\varepsilon}$ are as follows:

$C_{1 \varepsilon}=1.44, C_{2 \varepsilon}=1.92, C_{\mu}=0.09, \sigma_{k}=1.0, \sigma_{\varepsilon}=1.3$

The Realizable $\mathrm{k}-\varepsilon$ turbulence model can well describe the vortex motion of fluid, and has good convergence and stability, so the Realizable $\mathrm{k}-\varepsilon$ turbulence model is adopted in this paper.

\section{Calculation model, boundary condition and algorithm selection}

\subsection{Calculation model}

In this paper, a marine diesel engine is taken as the research object. The diesel engine type is in-line, four stroke, direct injection, water cooling, double cycle. The rated speed is $1500 \mathrm{r} / \mathrm{min}$, the rated power is $650 \mathrm{~kW}$. The ambient temperature is $45^{\circ} \mathrm{C}$, the atmospheric pressure is $100 \mathrm{kPa}$, and the atmospheric humidity is $60 \%$.

\subsubsection{Geometric model}

The three-dimensional model of diesel engine cooling water jacket is shown in Figure 1 below. The cooling water jacket of the diesel engine belongs to the lateral flow cooling water jacket. The water jacket inlet of the cylinder block is located at the air inlet side between the second and third cylinders. The water channel is arranged longitudinally at the air inlet side of the lower part of the cylinder block. After the coolant enters the cylinder block 
from the main water inlet pipe, it flows to each cylinder along the longitudinally arranged water channel. The water jackets of the adjacent cylinder blocks are connected with each other. After the coolant fills the water jacket of each cylinder block, it enters into the water jacket of cylinder head through the water supply hole of cylinder head. Each cylinder head has two water supply holes, one at the inlet and one at the exhaust side. The water jackets of cylinder head are independent of each other and are not connected with each other. The coolant flowing from the water jacket of cylinder head flows into the water outlet main pipe.

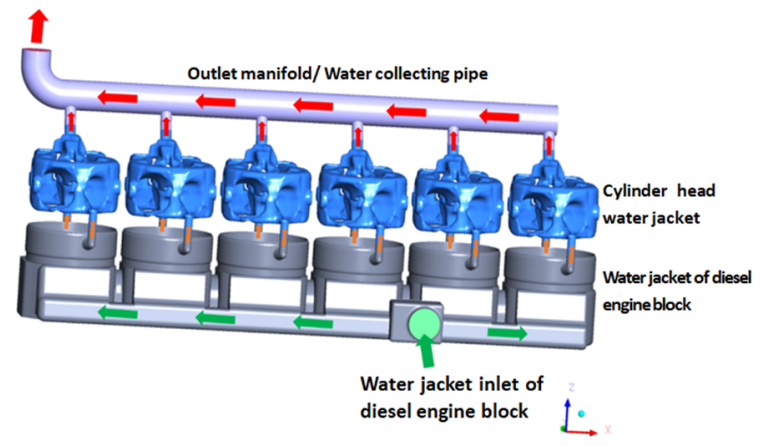

Figure 1. 3D model of engine cooling water jacket

The three-dimensional models of cylinder head water jacket and block water jacket of diesel engine are shown in Figure 2 3 below. As shown in Figure 4, the cylinder head water jacket can be divided into inner water jacket and outer water jacket. The coolant enters into the outer water jacket of the cylinder head through the water supply hole, cools the nose bridge area of the fire surface of the bottom plate, enters into the inner water jacket, and then flows to the outlet pipe.
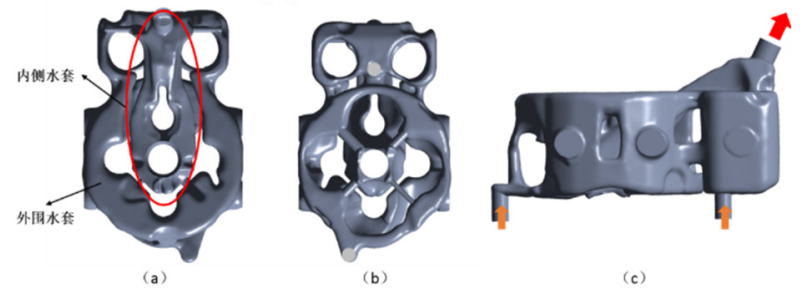

Figure 2. 3D model of cylinder head water jacket

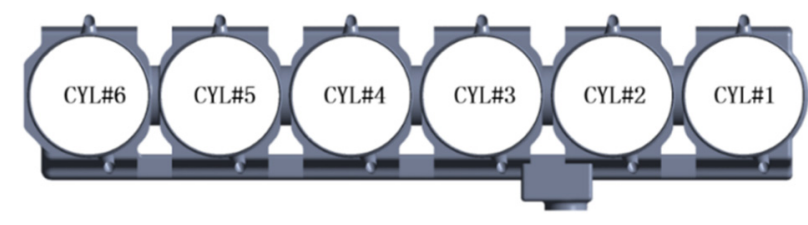

Figure 3. 3D model of water jacket

\subsubsection{Discrete model}

The automatic mesh refinement technology based on surface chord difference method provided by HyperMesh software is used to divide the surface mesh. The mesh quality is controlled manually, and then the volume mesh is generated from the surface mesh to complete the mesh generation. After several trial calculations, the size of the grid is $2 \sim 4 \mathrm{~mm}$, and the total number of grids is about 10.88 million. In the calculation, the FLUENT software is used to synthesize polyhedral mesh to improve the solution speed, and more than $90 \%$ of them are hexahedral elements. The boundary layer is drawn near the wall. The boundary layer is a two-layer grid with a total thickness of $0.5 \mathrm{~mm}$. Figure 4 below shows the grid model of cooling water jacket of diesel engine.

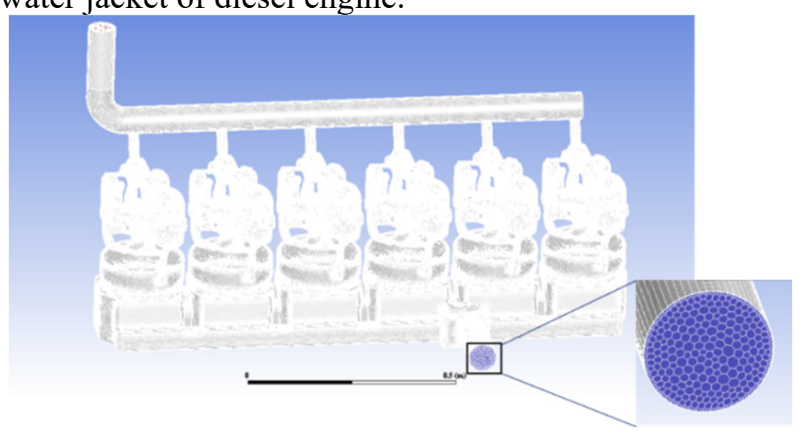

Figure 4. Cooling water jacket calculation grid model

\subsection{Boundary condition}

(1) Inlet boundary

The inlet boundary is defined as the mass flow inlet, and the inlet flow is the pump outlet flow. According to the formula: $I=0.16\left(R_{e D H}\right)^{-1 / 8}$, where $R_{e D H}$ is the Reynolds number calculated according to the hydraulic diameter.

(2) Outlet boundary

The flow field characteristics of integral water jacket of cylinder block and cylinder head were studied. Therefore, only one outlet is set, and the coolant is incompressible fluid. Considering the relative pressure, the outlet of cooling water jacket header is defined as the pressure outlet boundary.

(3) Wall boundary conditions

The stationary wall and no slip boundary conditions are adopted for the wall, and the default roughness constant is 0.48 .

\subsection{Algorithm selection}

The three-dimensional numerical simulation of diesel engine water jacket was carried out by using FLUENT software. The grid center method of the finite volume method (FVM) is used to establish the discrete equation, and the second-order upwind control equation discrete method is used. Simple algorithm (Semi-Implicit Method for Pressure-Linked Equations) was used to calculate the flow field. The Realizable $\mathrm{k}-\varepsilon$ turbulence model is adopted, and the steady-state calculation mode is selected, convergence after 3000 steps. The parameters of the boundary layer fluid near the wall are described by the standard wall function method, and the convergence criterion is the residual value of each variable (including velocity, momentum, temperature, turbulent kinetic energy, pressure, etc.) with an accuracy of 0.0001 . 


\section{Numerical calculation of flow field characteristics of cooling water jacket of cylinder block and cylinder head}

\subsection{Experiment verification}

Table 1 shows the simulation calculation value and experimental measurement value of cooling water flow of each cylinder when the total inlet flow is $400 \mathrm{~L} / \mathrm{min}$, the error between experimental value and simulation value is less than $5 \%$.

Table 1. Test value and Simulation value of each cylinder flow when the total inlet flow is $400 \mathrm{~L} / \mathrm{min}$

\begin{tabular}{ccccccc}
\hline \multirow{2}{*}{ Parameters } & \multicolumn{7}{c}{ Cylinder number } \\
\cline { 2 - 7 } & 1 & 2 & 3 & 4 & 5 & 6 \\
\hline Simulation value (L/min) & 64.15 & 67.46 & 62.01 & 68.51 & 71.33 & 72.69 \\
Test value (L/min) & 64.56 & 65.32 & 64.76 & 66.55 & 68.43 & 70.23 \\
Error (\%) & -0.633 & 3.283 & -4.252 & 2.943 & 4.235 & 3.508 \\
\hline
\end{tabular}

\subsection{Analysis of flow field characteristics of cooling water jacket of cylinder block and cylinder head}

The pressure field, streamline distribution and velocity field of cooling water jacket and the flow uniformity of each cylinder were analyzed under the rated condition of diesel engine.

\subsubsection{Pressure field analysis}

Figure 5 shows the cloud picture of the total pressure distribution of the whole water jacket. Figure $6 \sim 8$ are the cloud pictures of pressure distribution of cylinder head water jacket, body water jacket and outlet main pipe. It can be seen from Figure 5 that the pressure distribution of the water jacket is divided into four levels: the cylinder block water jacket, the outer layer of the cylinder head water jacket, the inner layer of the cylinder head water jacket and the water outlet main. There is a very obvious pressure drop between the two adjacent parts. The main reason is that the two adjacent parts are connected by small pipelines, and the structural area of the two connecting parts changes abruptly. The cylinder water jacket and the outer layer of the cylinder head water jacket are connected by two water supply holes of each cylinder. The outer
The error of the 3 th cylinder is large, but it is also within $10 \%$ of the allowable error of engineering research. Considering the influence of the flowmeter on the overall flow field distribution, the measurement error of the experimental instrument, the recording error of the measured value, and the simplification of some non critical areas by grid division, the maximum error of dimensional numerical simulation results of cooling water jacket of cylinder block and cylinder head are reliable. $4.252 \%$ is acceptable. The results show that the three-

layer of the cylinder head water jacket and the inner layer of the cylinder head water jacket are connected by six connecting holes (four connecting holes in the nose bridge area of the cylinder head bottom and two connecting holes near the water outlet of the upper part of the cylinder head). The inner layer of the cylinder head water jacket and the water outlet main pipe of the cylinder head are connected by the water outlet pipe of the cylinder head. The flow area at each connection is relatively small, which will cause obvious pressure drop.

From the first cylinder to the sixth cylinder, the water jacket pressure has an obvious downward trend. The main reason is that the inlet of the water jacket is close to the first cylinder, while the outlet is close to the sixth cylinder, so the back pressure at the outlet of each cylinder gradually decreases, which is also the reason why the flow rate of the last few cylinders (especially the sixth cylinder) is significantly higher than that of other cylinders. The total pressure loss of the water jacket of the whole machine is $30.3 \mathrm{kPa}$, in which the pressure loss of the engine block is $8.4 \mathrm{kPa}$, and the pressure loss of the cylinder head and the outlet main pipe is $21.9 \mathrm{kPa}$, which is equivalent to the pressure loss of similar models. Therefore, the flow resistance design of the cylinder block and the cylinder head is more reasonable.

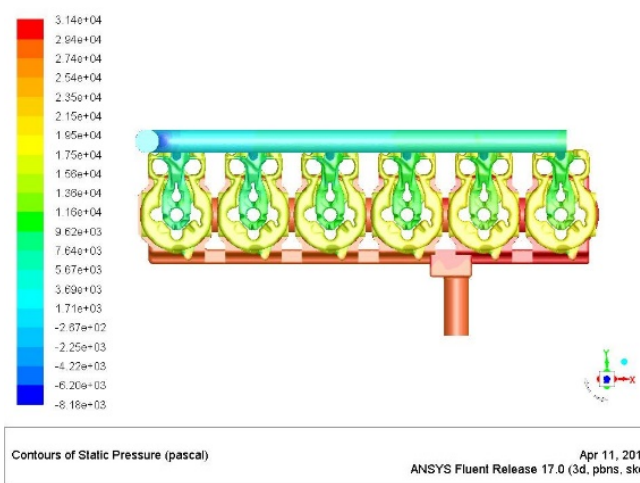

(a)
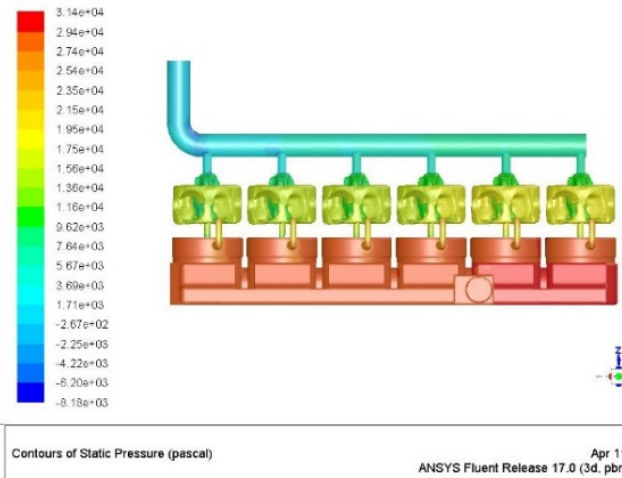

Figure 5. Pressure distribution of cooling water jacket 


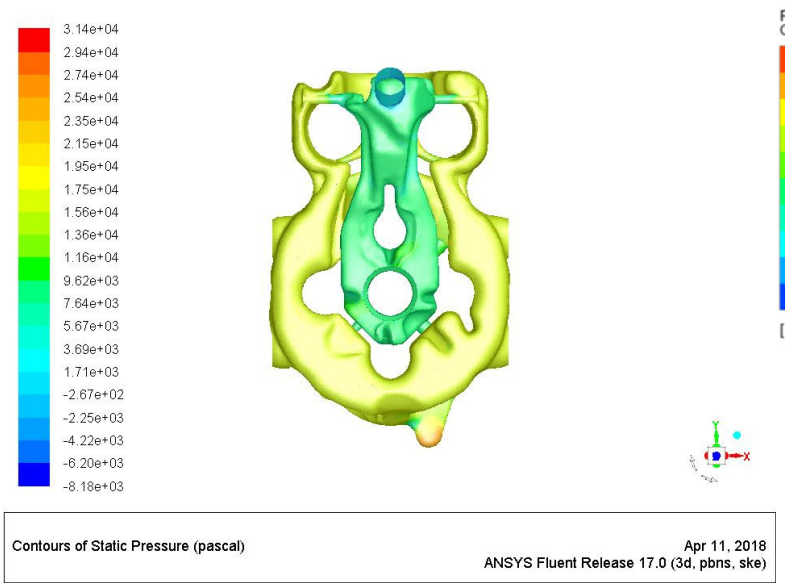

Figure 6. Pressure distribution of cylinder head water jacket
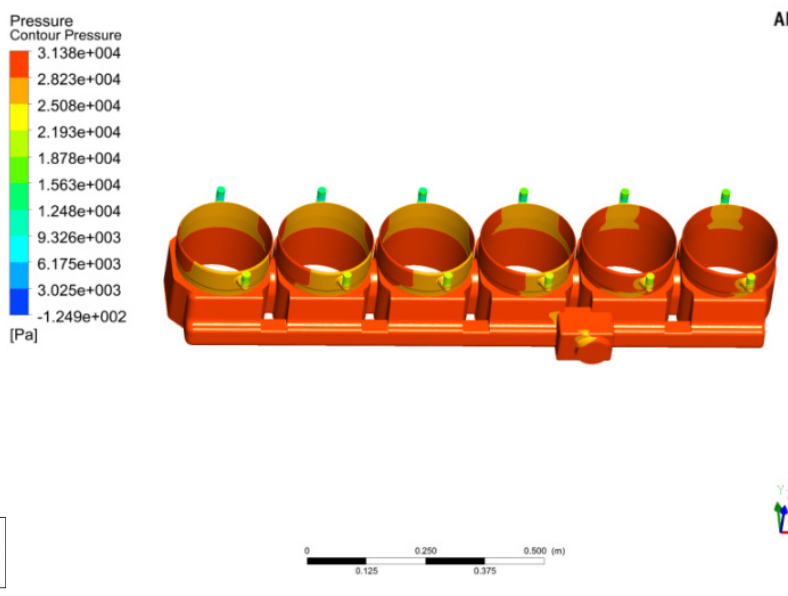

$\stackrel{2}{\longrightarrow}$

Figure 7. Pressure distribution of engine block

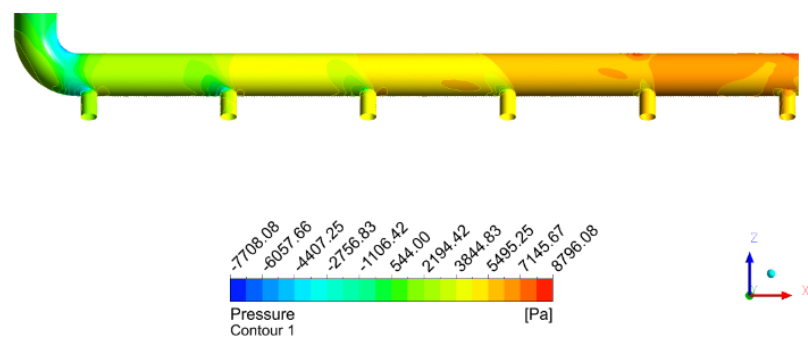

Figure 8. Pressure distribution of water collecting pipe

\subsubsection{Analysis of streamline distribution and velocity field}

Figure 9 shows the streamline distribution of cooling water jacket. After the cooling water enters the water chamber of the cylinder block from the main water inlet pipe, it is divided into two flows in the water chamber of the cylinder block. One flows along the circumference of the cylinder block, and the other flows upward due to the impact and extrusion, and flows into the cooling water jacket of the cylinder head through the water supply pipe. After the heat exchange between the cooling water and the wall at the lower part of the outer water jacket of the cylinder head, the cooling water flows into the upper part of the inner water jacket of the cylinder head through the water pipe, and finally converges at the outlet above the cylinder head.
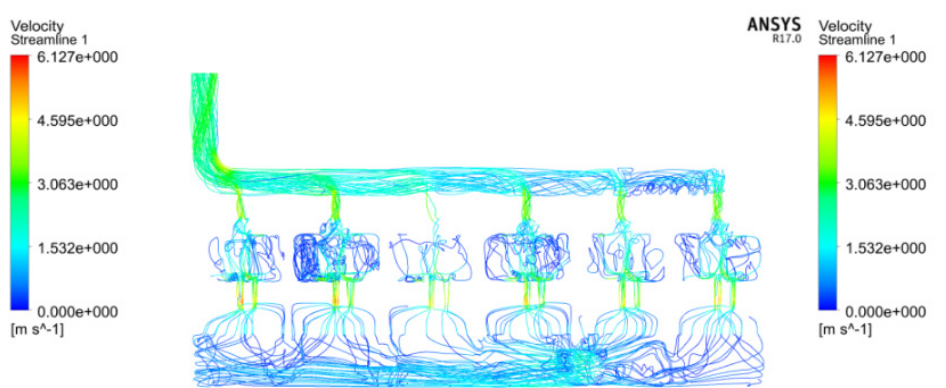

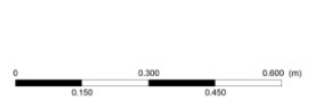

(a) $\stackrel{2}{\longrightarrow}$

Figure 9. Streamline distribution of cooling water jacket of the whole machine
In the cylinder head water jacket, the cooling water flowing into the cylinder head water jacket from the body water jacket through the upper water hole is divided into two paths to flow to the peripheral water jacket of the cylinder head. Figure 10 shows the diversion of the two inlet holes at the bottom of the water chamber and the cooling organization of the cooling water to the fire plate at the bottom of the cylinder head: when the cooling water enters the cooling water chamber of the cylinder head from the two upper water holes, a part of the cooling water flows around the air inlet and the exhaust port, and then flows into the inner water jacket of the cylinder head from 
the through hole of the water chamber at the head of the exhaust port, which can eliminate the flow around the water chamber at the head of the exhaust port Most of the remaining cooling water flows from the cooling channel around the "nose bridge area" to the cooling water cavity around the injector hole, and from here flows to the inner water cavity of the cylinder head.

Most of the coolant flow rate in the water jacket is above $0.5 \mathrm{~m} / \mathrm{s}$, the flow rate of the water hole on the cylinder head is $2 \sim 3 \mathrm{~m} / \mathrm{s}$, and the flow rate of the water cavity in the nose beam area of the cylinder head is $2 \sim$
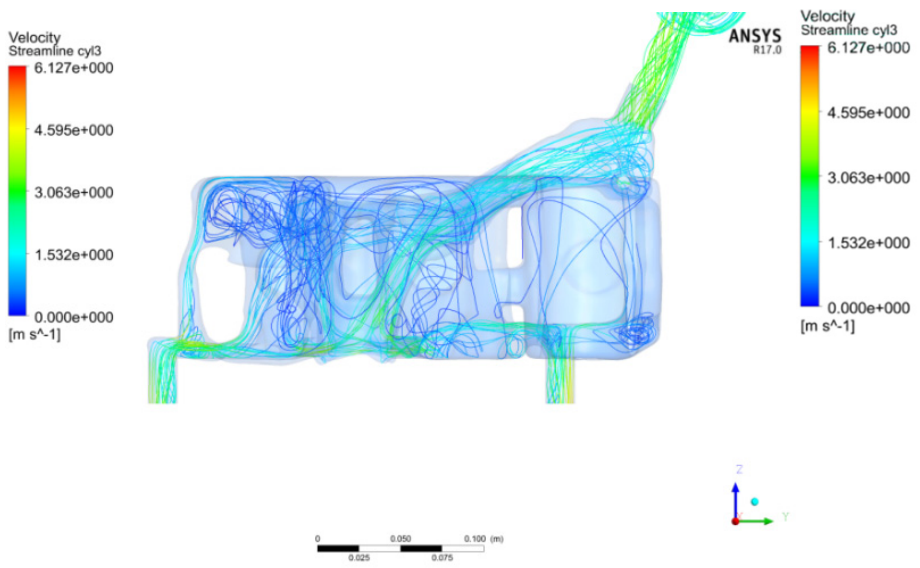

(a)
$4.5 \mathrm{~m} / \mathrm{s}$. Generally speaking, the cooling demand can be satisfied when the flow velocity in the bridge area is above $1.5 \mathrm{~m} / \mathrm{s}$. It can be seen that the flow structure of the cooling water jacket flow field of the diesel engine meets the cooling requirements. However, due to the influence of structural layout, when the cooling water flows in the body water jacket in a circumferential direction, part of the water will collide with each other, and it is easy to form part of the flow dead zone after mutual extrusion.

Figure 10 Streamline distribution of c ylinder head cooling water jacket

Figure 11 is the velocity distribution nephogram of the main outlet pipe. Combined with the pressure distribution nephogram of the collecting pipe in Fig. 8, it can be found that the total pressure of the outlet pipe from the first cylinder to the sixth cylinder gradually decreases, and the flow rate gradually increases, showing a very obvious level. This is mainly due to the continuous convergence of cooling water after flowing out from each cylinder head, the flow rate is increasing, and the flow area remains unchanged. In addition, it can be seen from the streamline diagram in Figure 10 (a) that the streamline in the main outlet pipe is in the shape of "twist", that is, there is a vortex flowing around the pipe wall in the pipe, and there is a dead angle at the entrance corner of each cylinder head to the main outlet pipe. This is mainly due to the right angle connection between the cylinder head outlet and the outlet main pipe, which has a large flow resistance.
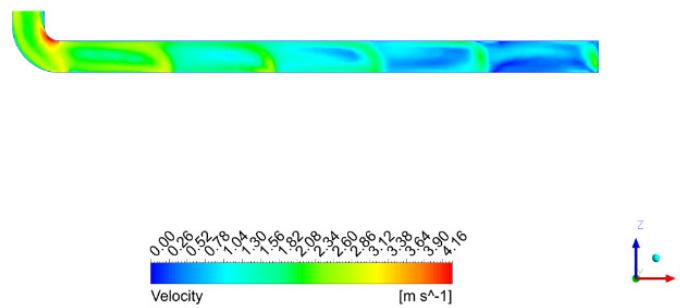

Figure 11. Velocity distribution of water collecting pipe

\subsubsection{Analysis of streamline distribution and velocity field}

For multi-cylinder internal combustion engine, the ideal situation is that the coolant flow through each cylinder is equal. But in fact, there is uneven cooling in each cylinder, which needs to be evaluated and analyzed. The uniformity of cooling water flow of each cylinder can be evaluated by the non-uniformity $\delta$ :

$$
\delta_{i}=\frac{m_{i}-m_{m}}{m_{m}} \times 100 \%()
$$

where $m_{i}$ and $m_{m}$ is the cooling water flow of the $i$-th cylinder and the average cooling water flow of each cylinder.

The cooling water uniformity of all cylinders is measured by the maximum non-uniformity. Table 2 shows the flow non-uniformity of each cylinder under the rated working condition of diesel engine. It can be seen from the table that, affected by the structural arrangement and inlet and outlet water pressure, the cooling water flow of the sixth cylinder near the engine outlet is the largest, while the water flow difference of other cylinders is small, and the maximum non-uniformity of water flow of each cylinder is $5.85 \%$, which can meet the requirements of diesel engine cooling. 
Table 2. Distribution of flow and flow nonuniformity of each cylinder under rated condition

\begin{tabular}{ccccccc}
\hline \multirow{2}{*}{ Parameters } & \multicolumn{7}{c}{ Cylinder number } \\
\cline { 2 - 7 } & $\# 1$ & $\# 2$ & $\# 3$ & $\# 4$ & $\# 5$ & $\# 6$ \\
\hline $\mathrm{m}_{\mathrm{i}}(\mathrm{L} / \mathrm{min})$ & 79.69 & 79.52 & 80.17 & 80.06 & 82.74 & 86.15 \\
$\delta(\%)$ & -2.09 & -2.29 & -1.49 & -1.63 & 1.66 & 5.85 \\
\hline
\end{tabular}

\section{Conclusion}

Taking a marine diesel engine as the research object, the CFD simulation of the flow field characteristics of the cooling water jacket of the diesel engine is carried out by using the FLUENT software. The pressure field, flow field and the non-uniformity of the flow rate of each cylinder of the cooling water jacket under the rated working condition are analyzed, which points out the direction for the structure optimization of the cooling water jacket. The results are as follows:

(1) Under the rated condition, the total water pressure loss of the water jacket is $30.3 \mathrm{kPa}$, in which the water pressure loss of the engine block is $8.4 \mathrm{kPa}$, the water pressure loss of the cylinder head and the water outlet main pipe is $21.9 \mathrm{kPa}$, which is equivalent to the water pressure loss of the same type of diesel engine, indicating that the flow resistance design of the cylinder block and the cylinder head is reasonable.

(2) Under the rated condition, the coolant flow rate in the water jacket of the engine block is about $0.5 \mathrm{~m} / \mathrm{s}$, and the water flow rate in the water cavity of the cylinder head nose beam area is $2 \sim 4.5 \mathrm{~m} / \mathrm{s}$. The cooling demand can be satisfied when the water flow rate in the nose area of cylinder head is kept above $1.5 \mathrm{~m} / \mathrm{s}$, which indicates that the cooling water jacket structure meets the design requirements of the cooling system.

(3) The cooling water flows in the diesel engine block water jacket in a circumferential direction, and some of the water flows collide and squeeze each other, which easily leads to the flow dead zone.

(4) The outlets of the water jacket of the cylinder head is connected at right angle to the outlet manifold, which leads to the "twist" shape of the coolant flow line in the outlet manifold and the existence of the flow dead zone at the corner of the coolant outlet of the cylinder head water jacket, which leads to the large flow resistance and the large energy loss of the flow field in the pipe

(5) Influenced by the position of cylinder jacket water inlet, the maximum nonuniformity of water flow in cylinder jacket is $5.85 \%$, which can be further optimized by adjusting the position of cylinder jacket water inlet.

\section{References}

1. W. Xiaohan, W. Hongrong. CFD analysis and optimization of cooling water jacket of an agricultural diesel engine based on database [J]. Journal of automotive engineering, 2016,6 (02): 125-130

2. S. Kaijin. Numerical simulation and optimization analysis of four cylinder diesel engine cooling system based on CFD [D]. Hefei University of technology,

\section{6}

3. W. Zhaowen. Flow analysis and heat transfer enhancement of cooling water in cylinder head of heavy duty vehicle diesel engine [D]. Huazhong University of science and technology, 2008

4. X. Dongsheng, Z. Huichen, Z. Xinwei. Numerical analysis of cavitation characteristics of diesel engine cylinder liner cooling water based on CFD [J]. Journal of internal combustion engine, 2010,28 (04): 368-373

5. Y. Yisu, X. Zhe. CFD analysis of cooling water jacket of automotive diesel engine [J]. Hyundai automotive power, 2008 (03): 38-41

6. Z. Zengliang. CFD analysis and experimental study on cooling system of tractor diesel engine [D]. Hunan University, 2015

7. Z. Libin. Development of NC machine tool for machining cooling water holes in cylinder head of marine diesel engine [D]. Dalian University of technology, 2015

8. Z. Hongwen. Research on improvement of cooling system of Yuchai $6 \mathrm{~m}$ diesel engine [D]. Guangxi University, 2013

9. L. Jilin, S. Lizhong, B. Yuhua. CFD simulation and optimization of cooling water jacket structure for 2D25 horizontal diesel engine[J]. Editorial Office of Transactions of the Chinese Society of Agricultural Engineering,2012,28(10).

10. S. Fontanesi, M. Giacopini. Multiphase CFD-CHT optimization of the cooling jacket and FEM analysis of the engine head of a V6 diesel engine[J]. Applied Thermal Engineering,2013,52(2).

11. W. Junjie, H. Rui, C. Xiaoqiang. Experimental measurement and Numerical Study on flow field of water jacket in cylinder head of diesel engine [J]. Mechanical and electrical engineering, 2018,35 (07): 708-712

12. Z. caifan. Matching design and performance optimization of engine cooling system [D]. Jiangsu University, 2017

13. Z. Xin. Reliability analysis of diesel engine cooling system considering common cause failure [D]. Jiangxi University of technology, 2017 